\title{
Algorithmic Long-Term Unemployment Risk Assessment in Use: Counselors' Perceptions and Use Practices
}

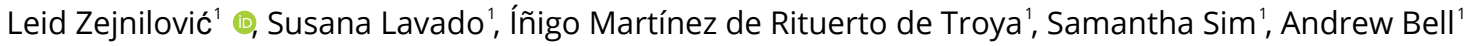 \\ ${ }^{1}$ Nova School of Business and Economics, Universidade Nova de Lisboa, Lisbon, Portugal \\ Keywords: human detachment and attachment to decision-making, street-level bureaucrats, algorithmic decision-making \\ https://doi.org/10.1525/gp.2020.12908
}

\section{Global Perspectives}

\begin{abstract}
The recent surge of interest in algorithmic decision-making among scholars across disciplines is associated with its potential to resolve the challenges common to administrative decision-making in the public sector, such as greater fairness and equal treatment of each individual, among others. However, algorithmic decision-making combined with human judgment may introduce new complexities with unclear consequences. This article offers evidence that contributes to the ongoing discussion about algorithmic decision-making and governance, contextualizing it within a public employment service. In particular, we discuss the use of a decision support system that employs an algorithm to assess individual risk of becoming long-term unemployed and that informs counselors to assign interventions accordingly. We study the human interaction with algorithms in this context using the lenses of human detachment from and attachment to decision-making. Employing a mixed-method research approach, we show the complexity of enacting the potentials of the data-driven decision-making in the context of a public agency.
\end{abstract}

\section{INTRODUCTION}

Algorithms are becoming widely adopted in public services as a means for both improving service efficiency and providing new services through the newfound capacity to process vast volumes of data. The appropriation of developments from industry and profit-driven enterprises by governments undergoing digital transformations has led to improvements in public services and innovation through the development of datacentric capabilities (Catlett and Ghani 2015). In public service practice, the outputs of the models trained by algorithms are usually embedded into software that supports routines relevant to the decision makers and those who implement them. The software, usually referred to as a decision support system, provides information that may support humans in completing part of a task or an entire task by analyzing large volumes of data, making a decision, and prescribing actions verifiable by humans (Gillingham 2019a; Wagner 2019; Raso 2017). The level of task execution completeness may also be referred to as the level of automation. There are high perceived potentials of the decision support systems in social work (Gillingham 2019a), which may be further fueling the enthusiasm for what is known as the digital era of governance (Dunleavy et al. 2005). Enthusiasm aside, recent implementations of the decision support systems in the social welfare sector have unearthed many challenges that originate at or are affected by the interactions of frontline workers (or street-level bureaucrats) and citizens, where the algorithm-informed or algorithmic decisions are interpreted for the citizens at the workers' discretion. The frontline workers' exercise of discretion, or how they make decisions within their job constraints, has been captivating scholarly interest for decades (e.g., Lipsky 2010). The introduction of algorithms at work only added to the complexity of the workers' tasks and the importance of this topic; these workers are simultaneously managing numerous policies and programs, trying to live up to social expectations, and coping with the constraints imposed by increasingly complex digital tools (Binns 2019; Hupe 2019; Raso 2017).

The algorithms may render the employees as the interpreters of results presented via simple user interfaces, often leaving them oblivious to the complex analysis that generated the results (Bader and Kaiser 2019; Lavalle et al. 2011). The opacity inherent to algorithms (Burrell 2016), the oversimplicity of the interfaces that present the results (Bader and Kaiser 2019), or the lack of adequate management of algorithms as the underlying data change over time may lead to frustrations or doubts about the outcomes of the algorithmic decisions (Lebovitz, Levina, and Lifshitz-Assaf 2019; Kellogg, Valentine, and Christin 2020). As a result, the algorithms at work may lead to the development of practices that significantly depart from the expectations in organizations (Bader and Kaiser 2019; Raso 2017), which in turn create a negative feedback loop that challenges the learning process from the data and the metrics used to evaluate the effectiveness of the algorithms, and ultimately diminishes the ability to improve the algorithms over time.

There is an ongoing debate about the degree of decisionmaking automation that should be used at the street level of hierarchy, which ranges from human intelligence alone, through its combination with algorithmic decision-making, all the way to fully autonomous algorithmic decision-making (Wagner 2019; Gillingham 2019b; Günther et al. 2017; Raso 2017). This debate is partly fueled by the existence of divergence between algorithmic and human decision-making logic (Bader and Kaiser 2019). Although evidence explaining these complexities at street-level decision-making is accumulating, there is still a need to extend the evidence base, as well as to extend our understanding of the nature of the interaction of algorithms and humans in public agencies, and the implications for the individual employees, organizations, and social welfare.

In this article, we study a hybrid, human-computer decision-making system within the context of a public employment service (PES). The objective of the study is to un- 
derstand the complexity of an algorithmic long-term unemployment risk assessment system, how it is used in practice, implications of the gap between the designated and the assumed roles of the system, and the potential of the system to contribute to the fulfillment of the organization's purpose: impactful support to the unemployed. Furthermore, this article seeks to expand present literature on the limitations and strengths of the interactions between human and algorithmic decision-making, which incompletely considers the individual and organizational impact of algorithms at work. To achieve the objective, we collected empirical data from managers and counselors from a PES in Portugal. More specifically, we conducted interviews with the management, two job visits in loco, and two focus groups with counselors. We further tested some of our findings with a survey of the broader group of counselors.

\section{BACKGROUND}

\section{PUBLIC EMPLOYMENT SERVICES AND ALGORITHMIC DECISION-} MAKING

Public employment services (PESs) are government agencies that provide vocational training and career counseling, and promote employment opportunities among both the unemployed as well as employed individuals looking to reskill, upskill, or pursue a new career path. In present-day PESs, as in most of the other public services, resources are limited and often oversubscribed (Lipsky 2010).

Many clients of PESs are from vulnerable or marginalized populations and may face personal and professional hardships, often because of their professional or socioeconomic status (Diette et al. 2012). PESs must help their candidates navigate uncertain labor markets characterized by fluctuating economic conditions and sometimes discriminatory hiring practices biased against sensitive groups, like older workers or people with disabilities (Becker, Fernandes, and Weichselbaumer 2019; Carlsson and Eriksson 2019; Kübler, Schmid, and Stüber 2018).

Historically, PESs are affected by global trends in public management. These trends are often greeted with elevated expectations, and subsequent changes in trends arise as a response to unmet expectations and mixed successes of previous trends. For example, the businesslike managerial approaches known as "new public management" dominated in the 1980s and 1990s (Hood and Peters 2004; Hupe 2019). That trend was followed by the rise of information technology usage, or the "digital era of governance," in the late 1990 s in response to the mixed success of new public management (Dunleavy et al. 2005).

Even though information technology is at the core of public administration tasks (Dunleavy et al. 2005), after more than two decades of experimentation, the current trend of algorithmic use in decision support systems remains in its infancy (Gillingham 2019b).

Presently, most PESs maintain high-touch interactions between counselors, or street-level bureaucrats (Lipsky 2010), and the citizens. To obtain rights to assistance, unemployed individuals must register at a PES and provide information about themselves and their job situation to the counselors. Based on the data at hand, and the information provided by decision support systems, the counselors interpret and implement policies, resolving ambiguities by considering the specificities of each case (Hupe 2019).

In democratic societies, it is desirable for public service provision to conform to the Weberian ideal of governance such that centrally devised rules need to be uniformly and equitably implemented. However, such implementations are hardly achievable because of the inevitable lack of rule specificity. Public policies often contain ambiguities and conflicts that need to be handled simultaneously (Zacka 2017). Since it is unlikely that all policies are well defined, the counselors often make decisions using their professional judgment instead of conforming with the detailed legal rule (Kagan 2010). This flexibility in applying the rules also implies that the counselors are under the scrutiny of their managers and the public. Namely, there are organizational constraints and goals as well as social norms and moral expectations regarding the public service. What is the source of this "rule and discretion" paradox, and why is it persistent?

When considering the distribution of public goods and services, Lipsky (2010) suggests that they are distributed differentially. In operational terms, triage, or categorization of cases based on the urgency and potential impact of the intervention, is a standard model of differentiation in PESs as well as other street-level bureaucracies. Frontline employees are given significant discretion in order to meet the demands of their workload, albeit discretionary judgments leave room for routine abuse. Counselors may make a biased decision, such as selecting top candidates who are most likely to succeed, or treat some clients preferentially (Lipsky 2010). The persistence of such biases is tolerated because street-level bureaucrats are expected to process all the cases and give form to the at times ambiguous and contradictory public policies (Zacka 2017). Street-level bureaucrats need to come up with solutions for a problem at hand based on the available regulations, their knowledge, and their experience, under time pressure and the cognitive burden of recognizing the idiosyncrasies of every individual. These factors and resulting decisions can be reasonably expected to vary significantly among counselors. Hence those who seek to design public services that are transparent and fair and offer equitable distribution of public goods are likely to see big-data-driven algorithmic decision-making as a step in that direction.

\section{ALGORITHMIC DECISION-MAKING, LONG-TERM} UNEMPLOYMENT, AND HUMAN DETACHMENT AND ATTACHMENT TO DECISION-MAKING

The availability of large amounts of data about human activity, increasingly affordable computational capacity to process the data, and the development of sophisticated machine learning algorithms have created a unique opportunity to tackle complex societal issues (Lepri et al. 2017). The economic value produced from the use of the algorithms is a typical driver of their advancement and implementation, enabling more accurate decisions, automating work, enhancing organizational learning, or pushing the innovation frontier and allowing new practices and processes or even externalizing services (Kellogg, Valentine, and Christin 2020).

Algorithmic decision-making (ADM) may be defined as the automation of decision-making via computerized procedures that transform large volumes of input data into desired outputs and may be considered as a way to standardize routine working decisions (Möhlmann and Zalmanson 2017; Gillespie, Boczkowski, and Foot 2014). In public services, ADM could improve efficiency, quality, and consistency of the delivery of services at optimal cost. It may also increase the availability of process information to all stakeholders and enable preventive action by predicting outcomes (Sunstein 2012). Today, many decisions are made or assisted by algorithms - for example, stock trading, policing, or hiring (see Lepri et al. 2017). Machines have an advantage over humans for routine tasks where patterns of action exist, due to their robust ability to learn rules from the 
data by processing more information than any human could alone. While there is no doubt about the vast potential of the automation of decision-making, there are also many challenges related to building, implementing, and maintaining decision support systems with embedded ADM.

Industrial psychologists and systems analysts have been studying the role of humans in human-computer systems for several decades, including the shift of responsibility for decision-making from humans to machines (Zerilli et al. 2018). With increasing advanced and affordable automation, more human-performed jobs will shift from operational to supervisory (Strauch 2018). An issue of having humans as supervisors is that they may miss noticing that there is a problem in algorithmic decision-making until significant damage becomes visible. Also, evidence suggests that human overreliance on algorithmic decision-making is an issue that afflicts experts and novice alike and is generally resistant to training (Zerilli et al. 2018). The potential scale of the impact of algorithmic decision-making is a source of significant concerns, which is why it is subjected to high standards of (i) transparency, or openness about the analyzed data and the mechanism underlying the model; (ii) accountability, or responsibility for the actions taken based on the decisions; and (iii) fairness, which is interpreted as the lack of discrimination or bias (Lepri et al. 2018). Let us recall the earlier discussion about the street-level policy implementation and discretion in decision-making by the frontline employees. Considering the weight of human decision-making and discretion in existing systems, some scholars question if we are guilty of counterproductive double standards: too many restrictions imposed on algorithms that were never imposed on humans and street-level bureaucrats (Zerilli et al. 2018).

Depending on decision factors, like the length of the task and the liability of the outcome, the systems that employ algorithms may be designed with varying roles for the algorithms and the humans. For example, Facebook has deployed algorithms to scan posts for offensive content, thereby handling the time and scale issues of the task. However, in the end, the decision to remove an offensive post from Facebook's platform must, in many cases, be "rubberstamped" by a human agent (Wagner 2019). Such a system is said to have "human-in-the-loop" and is considered a quasi-automation (Danaher 2016). As the decision-making takes place, the actual roles of humans and the algorithms may change, and defining and clarifying their roles has just begun (Bader and Kaiser 2019). Binns (2019) argues that some decisions require human discretion and cannot be made rules-based by an algorithm, such as determining what is just or fair; fairness can be derived only from the specific social and institutional context. The need for quasiautomation becomes more apparent when considering that many algorithms are "black boxes," meaning that their decision-making processes are not transparent or easily understood by humans. The lack of transparency inherent to complex models can result in a lack of accountability, which in some contexts can be mitigated by an assemblage of humans and computers (Ananny and Crawford 2018).

Although it seems that the true potentials of the decision support systems have yet to materialize, significant efforts have been invested in the introduction of software to record processes and generate high-granularity transaction data, allowing experimentation with algorithmic decision-making in PESs. For example, many PESs have adopted predictive modeling as a tool to forecast registrants' employability, in order to facilitate counselors' work of triaging the allocation of limited resources to those most in need
(Scoppetta and Buckenleib 2018; Sztandar-Sztanderska and Zielenska 2018; Loxha and Morgandi 2014; Matty 2013; Riipinen 2011; Caswell, Marston, and Larsen 2010; O'Connell, McGuinness, and Kelly 2010; Payne and Payne 2000).

In practice, there are different ways to implement triage for allocating interventions. For example, in some implementations, interventions are assigned to unemployed candidates according to an assessment (score) of employability, which is computed by a machine learning algorithm (Sztandar-Sztanderska and Zielenska 2018; Caswell, Marston, and Larsen 2010). However, as highlighted by recent reports, such tools may provide little added value on their own. To be effective, they must be well implemented and well integrated into the broader system (Lipsky 2010; Mostafavi, Liu, and Barnes 2015). Ultimately, the success of such tools depends on their adoption by the counselors (Lipsky 2010). There are few regulations and laws in place governing the interactions between case counselors and the unemployed. For example, a study of Poland's PES system revealed that case counselors are not always transparent about the use of the profiling system with the unemployed (Sztandar-Sztanderska and Zielenska 2018). Several studies analyzed the effectiveness of profiling systems (Lipsky 2010; Mostafavi, Liu, and Barnes 2015; Weber 2011) and how profiling tools are used by counselors in practice (Weber 2011; SztandarSztanderska and Zielenska 2018). However, while the extant scholarly work shows that frontline employees struggle to use the systems that employ AMD with poorly implemented off-the-shelf software interfaces (e.g., Raso 2017), the evidence base is still weak and arguably incomplete.

The central aim of this study is to contribute to the understanding of the public service employees' perceptions and their use of algorithms for decision-making. We are exploring the complexities emerging from working with algorithms via decision support systems, in addition to the "regular" complexities of implementing public policies and resolving the associated ambiguities for citizens, within a resource-constrained environment and under the social expectation of human, fair, and equitable service. We follow the approach of Bader and Kaiser (2019) and employ the concept of human detachment from and attachment to the decision-making process (Hennion 2017) to understand the interactions of street-level bureaucrats with algorithms in the context of algorithmic decision-making for benefits allocation to help the unemployed. Attachment in this context refers to human engagement in the decision-making: how much do they hold to it, and are they being held by that decision? Detachment is the opposite: low human involvement in the decision-making process.

While the work of Bader and Kaiser (2019) focuses on the mediating role of the user interface, our goal is to understand organizational factors and individual perceptions that may influence the emergence of different human practices and challenge the "rule or discretion" dilemma in the age of algorithms.

\section{RESEARCH CONTEXT AND METHODS RESEARCH CONTEXT}

The Portuguese Public Employment Service, Instituto de Emprego e Formação Profissional (IEFP), has been serving the public since 1979. As of December 2019, around 291,500 unemployed people were registered at IEFP centers. The Portuguese national statistics institute reported the unemployment rate in 2019 to be 6.5 percent. In early 2012, the Portuguese government recommended the use of a triage protocol to differentiate the allocation of benefits to the un- 
employed, coinciding with high unemployment (15.5 percent) as a result of the 2008 economic crisis in Portugal. In the same year, 2012, IEFP implemented a risk-assessment (profiling) system based on several logistic regression models trained on data from 2009 and 2010. Logistic regression is a statistical method that, in this case, predicts a probability of an individual becoming long-term unemployed (LTU), defined by the International Labor Organization as a period of twelve consecutive months or more in search of work (ILO KILM 2016). The long-term unemployed are a salient segment of the unemployed population because of the compounding difficulties of finding work when one has remained out of work for an extended period. The final score calculated by the model implies the candidates' risk, and they could be assigned to a low-, medium-, or high-risk profile according to a cutoff value set on the risk score. The features included in the model describe candidates' demographics (e.g., age, gender), their professional background (e.g., desired profession and professional status before unemployment), and their current situation (e.g., whether they are receiving welfare). The outputs of the model are embedded in the PES-wide information system. The use of the models' outcomes is mandatory for each registration of an unemployed person, and the relevant decisions are stored in a centralized database. Below, we detail the interactions between a counselor and the unemployed person and between the counselor and the PES-wide information system that shows outputs of the model and registers the decisions as to the decision support system.

In an unemployment center, clients are physically present, either to register or to discuss their situation with the counselors as their unemployment prolongs over time. The clients are served on a first-come-first-served basis, and there are no dedicated counselors in the centers. The counselors have an information system's interface on their screens, with information that supports their interaction with the client. The required data-collection fields are manually populated by the counselors, who register the data reported by the client, their interaction, and the relevant takeaways from it. Upon collecting the client data, the riskassessment model produces a numeric risk score and categorizes the risk in one of three categories (low, medium, and high). The model that calculates the risk and the factors underlying the risk-assessment results are opaque to the counselors. The final decision on the prescription of interventions to help the unemployed person through is left at the discretion of the counselor. In practice, counselors define a personal employment plan (PEP) together with the candidate, specifying activities the candidate should undergo, such as specialized or general training sessions, job interviews, or other forms of active job search. At IEFP, these activities are referred to as interventions. The counselor is advised to include specific types and numbers of activities in the PEP in proportion to the estimated risk (a higher risk requires a more intensive $\mathrm{PEP}$ ). However, the risk profile only sets the minimum activities the PEP must include by type. In practice, counselors may propose additional interventions if the plan complies with the minimum requirements.

Importantly, the counselor may manually assign a candidate to a different risk profile, overriding the assignment made by the algorithm. The counselor is free to do so at any point during the candidate's unemployment period. If the counselor wishes to change the profile attributed to the candidate, the counselor needs to justify the decision by selecting one or more predefined categories, such as "Life circumstances," "Access to public transport," or "Profession- al circumstances." However, a meager percentage of profiles are changed-the mean rate of change by counselors is 2.4 percent $(\min =1.6$ percent, $\max =4.2$ percent, std $=0.8$ percent). Observing dynamics of decision-overriding over time, we can observe increasing engagement in the first two years, with a peak in 2013 of 4.2 percent and a sharp drop to only 1.6 percent of decisions changed in 2019.

The algorithm is applied only at the beginning of a new registration, meaning that a candidate will have the same risk score throughout the entire unemployed period. A candidate who has already been registered for eleven months could still have a low risk status, even though the likelihood of the candidate's becoming LTU would have statistically increased since the time the risk score was first calculated. Also, the model was not further developed, and it has remained in use until the present day. This poses a challenge for the long-term validity of the system. Namely, all predictive models become less accurate over time if they are not retrained when underlying data changes (Ackermann et al. 2018), which is known as "concept drift" and indicates that the model features that are predictive of a target (long-term unemployment in this case) change over time.

Given the context, we aimed to investigate how a riskassessment system has been implemented in employment centers of the Portuguese PES, how the counselors' decision-making supported by algorithms takes place, and what the perception of the performative role of the algorithmic risk assessment of LTU is in their day-to-day work.

\section{RESEARCH METHODS}

\section{QUALITATIVE ANALYSIS}

The first step in this project was interviewing the key stakeholders from the IEFP, managers of the statistics and the department for employment, as well as two employees responsible for the design and implementation of the riskassessment algorithm. The interviews were semistructured and served to inform us about the designated role of the risk-assessment tool, the managerial perceptions of its use in practice, and its perceived effects. As part of a broader initiative, two of the coauthors went to visit two regional unemployment centers, where counselors receive registrants, provide advice, and allocate benefits. The objective of the visits was to observe the operations and talk to the counselors at their workplace. With the information acquired from the interviews and visits, a focus group study was designed by following Morgan's (1997) guidelines.

Only counselors with at least one client were considered. To capture varied perspectives, counselors participating in the focus group had (i) different years of experience, (ii) diverse average workloads, and (iii) different demographic characteristics. Middle managers who work in IEFP headquarters and supervisors in IEFP regional centers selected twelve counselors who all agreed to speak with us.

We conducted two focus group sessions, each with 6 counselors, sampled from five out of eighty-three centers in continental Portugal.

The final sample had 8 female counselors (67 percent) and 19.3 mean years of experience $(\min .=1, \max .=36, \mathrm{std}=$ 13.4). Overall, the counselors' population consists of 1,089 counselors, of whom 75 percent are female, with a mean age of 49.7 and 19.3 average years of experience. The average number of clients seen by a counselor per day ranges from 1 to 43 clients for 2018. Monthly, these values range from 21 to 918 clients. These data were provided by the IEFP's statistics office. Note that we have excluded all the counselors with less than one client; the remaining sample was 
800 counselors.

The homogeneity in segmentation (see Morgan 1997) was not a significant concern, as the generally observed behavior among the counselors is similar.

The focus group sessions were conducted in March 2019 by two of the coauthors. Each session lasted for about two hours. They were conducted in Portuguese, the native language of the interviewer and the participants. All focus group conversations were audio-recorded after receiving the counselors' consent (none opposed). The recordings were then transcribed by a Portuguese native speaker, preserving the anonymity of the participants.

The focus groups followed a prepared script, which included two main themes. The first theme pertained to the usage of the system in the counselors' day-to-day work and whether they trust the system and perceive it to be useful. The second theme was about the changes that the counselors would like to see in the system.

The results of the focus groups were analyzed through thematic analysis, an approach used to extract patterns of meaning (themes) from qualitative data (such as interviews) by coding extracts of the data with a set of succinct labels to reveal overarching themes (Braun et al. 2019). In this study, we employ inductive thematic analysis, where coding and theme development are directed by the data. As the codes and themes emerged, the interpretations and disagreements among the authors were resolved first through an exercise of sense making, and then through an exploration of literature and reflections about novel contributions. During this process, the candidate's theoretical lenses emerged.

Qualitative methods are not without limitations. One potential issue is that any attitude or belief captured in interviews or focus groups is an artifact of these methods through social construction (Pearson and Vossler 2016) or strong group polarization (Isenberg 1986). To offer a better perspective on the counselors' interactions with the decision support system and to be able to gather data from a larger sample of counselors, we also included survey methodology.

\section{THE SURVEY}

We also conducted an online survey among the counselors, using Qualtrics surveying software. The invitation to fill out the survey was sent in October 2019 by the statistics department manager via email, with a short introduction to the purpose of the survey and her request to help with the research. In total, 247 counselors from twelve IEFP centers across Portugal received the invitation. We received 144 attempts to fill out the survey, of which 89 were unique and complete, a 36 percent response rate.

We asked for the respondents' demographics, effort expectancy regarding the use of the AMD risk assessment tool, its performance expectancy, and behavioral intention to use the tool to support decision-making if its use becomes optional-currently, its use is mandatory. The scales for the latter three questions were adopted and adjusted from the unified technology acceptance model (e.g., Venkatesh, Thong, and $\mathrm{Xu}$ 2016). In this article, we provide only the relevant descriptive statistics that show the distribution of attitudes across the counselors.

In addition, from the transactional database of the PES, we obtained an analysis of the number of interventions that the counselors allocated to the unemployed for each of the three risk groups in the past two years, to understand the link between the prescribed and the in-use practices.

\section{FINDINGS}

During the visit to the unemployment center and by observing the work of the counselors and talking with them, there was a strong indication that the time spent on considering the information provided by the decision support system is quite low. The same reasoning was echoed by the management, as they recognized that the information is offered in the form of a profile and a risk score and that the focus is indeed on the conversation between the counselor and the registrant. The counselors also indicated that it is unclear whether the time spent to change the decision is worthwhile, while it certainly is time-consuming because of the interface design.

\section{ATTACHMENTS AND DETACHMENTS FROM DECISION-MAKING:} ANALYSIS OF THE FOCUS GROUP SESSIONS

As the interpretation of the codes and themes from the focus group transcripts took place, the concepts of detachment from and attachment to decision-making by counselors (Hennion 2017; Bader and Kaiser 2019) have been adopted as theoretical lenses. The principal reasons for this decision were that it allows the dual nature of contextual factors to surface, and it is closely related to the decisionmaking process, the central theme of this study. In the following text, we first introduce the dimensions already identified in the literature and then introduce the new ones.

\section{THE DETACHMENT OF THE COUNSELORS FROM THE RISK-} ASSESSMENT DECISION

Spatial and temporal separation. The algorithmic risk-assessment tool is informed by the millions of observations of interactions between the unemployed and the PES, and the insights from the analysis of these interactions are materialized as an output of an algorithmic model. In this specific case, the applied machine learning approach is logistic regression, and the model is an equation that, after feeding the input data, results in a number that can be interpreted as a probability, or the risk score. While the limitation of the tool is that the model is almost a decade old and does not update over time, the amount of historical information processed (the temporal window) to generate the risk score is still significantly higher than the information that a counselor can obtain and process in the meeting slot of about twenty to thirty minutes that is typically allocated to an unemployed person. These factors increase the temporal detachment of the counselors from the decision-making. Also, most data that are relevant to qualify as an input into the risk-assessment algorithm are either reported by the unemployed or come from external sources (like social security services); hence they are not directly observable by the employee, arguably creating a partial spatial detachment from the decision-making.

Rational and political distancing. In the case of the allocation of interventions to the unemployed, there is a triangular arrangement: the information system interface that imposes a standardized data collection and offers a simplified output of the algorithm as information for the counselors; the unemployed, who receive the benefits; and the counselors. In such an arrangement, different situations emerge among the three actors that define how the risk assessment of LTU is concluded and how interventions (benefits) are allocated to the unemployed. Although the counselors can override the automated categorization of risks, very few counselors admitted to doing so. Counselors from the focus groups mentioned that when the system was implemented, it was common for them to alter the system 
manually. They perceived that the system was central to organizational policies, and they felt encouraged to pay attention to it. With time, they started feeling that the system was no longer relevant; hence they were detaching themselves from the decision of risk, at least at the level of interaction with the interface. It is a rational decision that is influenced by the counselors' perception of the political importance of the risk assessment. In addition, the choice to almost always formally agree with the automated decision of risk of becoming LTU is somewhat consequential of the above-mentioned time constraint of a typical meeting. In twenty to thirty minutes spent with each person, counselors need to establish a rapport with the candidate, enter their information into the database, and answer any questions the candidate might have. Counselors mentioned that they had no time to conduct an in-depth analysis of a candidate's profile to accurately assess their LTU risk in such a short period of time. It was easier to simply accept the score and move on to other tasks they perceived as more important. Given the short time allotted to each appointment, the counselors' concern was also whether they would be more biased than an automatic system in their risk assessment.

Infrastructural and procedural distancing. Although the counselors could override the system when thinking that the algorithmic risk assessment was wrong, the counselors mentioned that the information system's user interface demotivates them from doing so. Namely, the interface requires counselors to justify the change by selecting from a list of preselected categories. Searching through the options in the list is perceived as time-consuming, and the options provided are considered insufficiently intuitive or informative. To some counselors, the tool was "another bureaucratic task" to be completed in order to continue navigating the software system as they served their candidates. It was considered as part of an inadequate work procedure, which further distanced the counselors from being engaged in risk assessment decision-making. In other words, infrastructure introduces obstacles that employees cannot overcome, so they distance themselves from the officially registered decision. On top of the infrastructure, the organizations may introduce burdensome, nonessential procedures that may detach the employees from the decision-making.

\section{ATTACHMENT OF THE COUNSELORS TO THE RISK-ASSESSMENT DECISION}

Infrastructural, procedural, and contextual proximity. For the same reasons that the information system design may lead to counselors' detachment from the risk-assessment decision, it could lead to attachment to their decision-making. To continue the argument presented above, the counselors perceived changing the risk profile as inconsequential. They shared that a risk score has little impact on their overall work with the candidate. The established procedure includes only a recommendation of broad categories of interventions (e.g., attending an educational or training course, attending a job-seeking orientation session) that do not necessarily address candidates' immediate needs (e.g. an intervention in order to obtain a high school diploma). The system presents the risk score and the risk profile without further explanations or the potential mitigation of the risk. Hence it forces the counselors to think more about the risk and the appropriate path to help that specific unemployed person. Counselors mentioned that they follow other criteria to select candidates for specific interventions, such as the candidate's age or education, updating the PEP as needed. For instance, young people, who often are categorized as low risk, are more often selected as potential can- didates for interventions such as internships. Thus some counselors believe that someone who is assigned a high-risk score does not necessarily receive more help than someone who is assigned a low or a moderate risk score. In other words, the work procedure and the requirement to produce a personal employment plan with the allocation of the interventions force the counselors to develop stronger attachment (one that implies higher commitment in time and thought process) to the risk assessment, to understand more deeply the context of the unemployed person, and often to totally ignore the risk assessment generated by the algorithm.

Algorithmic opacity and distrust-invoked engagement. The reasons for accepting the automatic profile are unrelated to belief in the accuracy and trustworthiness of the system's predictions. On the contrary: when asked to estimate how frequently the system was correct, the participants either converged on an estimated accuracy of around onethird or were unable to make an estimate, explaining that they paid little attention to such evaluations of the system. Distrust is mostly related to the lack of understanding of the algorithmic decision, or to the algorithmic opacity. All focus group participants strongly agreed that they would be better able to contextualize the risk score, to interpret it, if they knew how it was calculated. In other words, the opacity of the algorithmic risk assessment contributed to the evolving distrust of the risk category felt by the counselors, as they could not understand why the risk was high or low, and which actions they could take to prevent adverse outcomes. Without the needed information about the algorithmic decision, the counselors become more engaged in their own decision-making.

Affective adhesion. While one may expect that after some time, discussing the very personal and challenging situation of being unemployed becomes routine, a natural human reaction is to feel empathy and become more involved (attached) in the risk decision-making process. One counselor remarked, "I don't look at it [the score] . . . I look at the person in front of me." Affection is also reinforced by the value system instilled in the foundation of the PES, to help citizens in a time of hardship. In addition, public image and public opinion have a strong effect: how the public may perceive the efforts invested and the effects of assistance that counselors offer, as their work is financed from taxpayers' money. Such public scrutiny is something that the counselors experience in their daily interactions with the unemployed, and it generates strong emotions. All these factors contribute positively to human (attachment) assessment of the risk and the consequential allocation of the interventions.

\section{ATTACHMENTS’ NEGATIVE PERFORMATIVE EFFECT}

The findings from this study corroborate previous work (e.g., Bader and Kaiser 2019; Kellogg, Valentine, and Christin 2020), which suggests the unclear and often unbalanced involvement of humans in the decision-making process when their involvement is expected. The need to react in a short period and with the empathy-driven objective to help a person in front of them creates situations that require the counselors to manipulate the system. Namely, although there is a legal recommendation to give more help to the unemployed who are at high risk of becoming longterm unemployed, the counselors often treat the automated risk assessment as a bureaucratic task that stands in the way of reaching the most important functional part of the interaction with the unemployed-the intervention allocation. By formally accepting the classification outcomes of 
Table 1. Descriptive statistics about the use of the algorithmic risk assessment of the long-term unemployment system.

\begin{tabular}{|c|c|c|c|c|}
\hline & Mean & Min & Max & Std Dev \\
\hline Age & 49.0 & 29 & 63 & 6.7 \\
\hline Gender & 0.79 & $0(\mathrm{M})$ & 1 & \\
\hline Effort expectancy* (E.g., the system is easy to use.) & 4.8 & 1.5 & 7 & 1.0 \\
\hline Performance expectancy * (E.g., the use of the system increases my productivity.) & 3.9 & 1 & 6.4 & 1.3 \\
\hline Intentions to use the algorithmic risk assessment if optional.* & 5.5 & 4 & 7 & 0.8 \\
\hline
\end{tabular}

* 1 = strongly disagree and 7 = strongly agree. From the unified technology acceptance model (Venkatesh, Thong, and Xu 2016).

the algorithmic risk-assessment tool even when they disagree with it, the counselors miss the opportunity to contribute accurate risk scores to the database. The database registers formal agreement and not the counselors' opinion of the risk. Hence the data does not reflect the true drivers behind the benefits allocation that is in the personal employment plan.

To help unemployed people, some counselors reach out to additional sources of data: "I use other [than risk score] information, such as how long they've been unemployed, their level of schooling, their area of work [ . . . ] to help them." While developing a better understanding of the unemployed individual's situation with the additional data is positive, the fact that the feedback, recorded as the accepted risk assessment, may be inaccurate and incomplete is a negative effect of counselors' attachment to the decisionmaking.

\section{THE PERFORMANCE-USE PARADOX: SURVEY RESULTS}

The analysis of the focus group interviews reveals the complexities of the system's use dynamics and challenges regarding counselors' involvement in the decision-making process. As one reads through the article, the impression of negativity for the algorithmic risk assessment and its representation becomes quite notable. But the survey results (table 1) suggest that despite the criticism, there is a strong sense of the need for the algorithmic risk score.

Namely, none of the 89 respondents disagreed with this statement: "Assuming that I can opt to use or not use the risk-assessment system, I intend to use it"; the average answer was between "Somewhat agree" and "Agree." In other words, although the qualitative analysis suggests that the risk assessment is an obstacle, there is still a favorable attitude toward usage. Survey results reveal that counselors' slightly positive attitudes toward the system's ease of use are contradicted by perceptions of the system's weak performance. The performance expectancy is differently perceived by male and female respondents; men held significantly more positive views than women, and t-test analysis does not reject the alternative hypothesis of the mean difference (mean(Male) - mean(Female)) being higher than 0 $(\mathrm{p}<0.001)$.

The survey evidence suggests a seemingly paradoxical situation, where the counselors prefer using a system that has little value for their productivity, as observed in the survey results and during the focus groups.

The contradictory results of the focus group study and the survey raised some issues. It is conceded that the survey results may not be representative of the reality on the ground. The voluntary nature of the survey meant that the
89 respondents may have self-selected (Bethlehem 2010) and do not represent well the population of counselors. The counselors may have also avoided reporting socially undesirable behavior (Foddy 1993; Dodou and de Winter 2014). For these reasons, we verified the results in postsurvey analysis, following up with additional intervention data analyses and a meeting with two PES middle managers.

\section{POSTSURVEY ANALYSIS}

To further explore the algorithmic risk assessment in use, we investigated the average number of allocated interventions and their distribution over the risk segments determined by the algorithm. Effectively, there is very little difference regarding the number of interventions, except for the group of people with disabilities who receive, on average, up to 1.5 more interventions as a high-risk profile than the other two risk profiles.

Upon completion of all the analysis, we reached out to two PES middle managers. The paradoxical result did not surprise them. Their interpretation is that despite potential ambiguities, the algorithmic risk assessment provides additional information and completes the formal element of registering the decision-making. What matters to the counselors is helping the unemployed and achieving any of the targets set by the management in the allocation of the interventions.

The low variation in the number and type of interventions across the risk profiles was seen as a consequence of inaccurate records of risk, lack of interventions available to the counselors, adherence to different organizational targets-like allocation to a specific type of intervention-or a combination of factors.

\section{DISCUSSION}

Over the past two decades, the more than half-centuryold promise (Simonite 2015) of automated algorithmic decision-making finally started materializing (Harris and Davenport 2005). But, as this and other studies show, integration of algorithms in routines of frontline employees and their maintenance and impact measurement is anything but straightforward (e.g., Bader and Kaiser 2019; Kellogg, Valentine, and Christin 2020; Raso 2017; Newell and Marabelli 2015). In developing our discussion, we consider the perspectives of frontline employees, organizations, and policymakers.

The analysis of focus groups and interviews with key stakeholders suggests that the interactions between frontline employees and algorithms are heavily influenced by organizational procedures, clarity of information provided 
as an algorithmic output, and the interface over which the output of algorithmic decision-making is presented to the employees. Organizational procedures are the critical elements of the interaction, as they define the roles and responsibilities of both the human and the algorithmic agent in decision-making. Challenges arise when procedures are incomplete and when many regulations need to be considered simultaneously for service delivery (Zacka 2017). The Portuguese PES has a strong focus on the human side of their work, recommending counselors to take into consideration the context of each case. At the same time, the measures adopted as a response to the 2008 economic crisis, like the recommendation to implement risk profiling or targets in the distribution of some benefits, aggravate an already complex decision-making process. Our findings suggest that counselors and algorithms are jointly part of the decision-making process, but the emerging assemblage seems to not be the most effective one. The procedures oblige counselors both to work with the outputs of algorithms, as risk profiles are mandatory, and to adhere to other priorities in distributing benefits, related to upper-management policies. In practice, counselors rarely rely upon algorithmic risk scores, according to the findings from the focus groups and the interviews, but do consider factual evidence from other data about unemployed people. The frontline employees also complain that it is hard for them to understand the basis for the algorithmic decision. Our inspection of the PES database revealed a very similar distribution of interventions over three risk bands (high, medium, and low risk), and the only notable difference is for categories of people with disabilities. "Sometimes we need to reach targets in the distribution of specific interventions" is among explanations offered by one of the middle managers for the similarity in the distribution. Another plausible explanation may be that the counselors facing ambiguous risk-score output and insufficient diversity of the available interventions for different cases fall back on the usual recommendations that allow them to continue work.

Resonating with previous research (e.g., Raso 2017; Bader and Kaiser 2019), the frontline employees are simultaneously handling challenges of decision-making based on algorithms and individual context and poorly designed user interfaces of programs that show algorithmic outputs. Unlike the frontline employees of Ontario Works, who use offthe-shelves software (Raso 2017), the Portuguese PES uses custom-made interfaces. Yet, in both cases, the system has not been designed or maintained with sufficient attention to the ease of use and, related to that, the quality of data collection. It is difficult, even impossible sometimes, for the frontline employees to register their true actions or choices regarding service delivery in the system. As a result, they may be entering the wrong information in the database. So the ideas of efficiency, transparency, and tractability in public administration, which are among the principal drivers of the implementation of decision support systems (Gillingham 2019b), fail foremost at the interface level. One way of dealing with such an issue is to include interface design as a task where experts interested in data quality will be included. Registration of wrong data produces short- and long-term negative consequences, by diminishing our ability to understand what was happening in the past, to analyze and improve policies, and to advance toward useful automation.

A theoretical contribution of this research is what we refer to as a performance-use paradox. The triangulation of empirics gathered from focus groups, interviews, and surveys reveals a paradoxical situation. From qualitative analy- sis, one can deduce that there is a general notion of negative experience in working with algorithmic risk assessment. The use of risk profiling is mandated but effectively ignored in most cases. The survey results are also indicative of such a situation, suggesting a weak expected performance. Rationally, one would expect that if such a system's use becomes optional, it would not be used. Yet, if we consider intentions to use as a proxy for real behavior (Ajzen 1991), survey responses indicate the opposite; even if the system becomes optional, there is a strong preference toward continued use of algorithmic risk assessment. What drives this paradox?

One explanation of this situation emerged from the focus group study. We learned that the counselors feel the need to consider large volumes of data, and the risk score approximates that. But the perceived usefulness of this score is low, and they prefer actionable intelligence over a simplified interface with a risk score and the profile category. Actionable and informative intelligence is the one that suggests the paths of possible actions and connects to data sources that are hardly accessible to the counselors and certainly too much of a cognitive burden for a twenty-five-minutelong meeting.

The seemingly contradictory behavior may also be explained as a form of strategic choice of frontline employees. Algorithmic output offers a potential argument regarding the choices counselors make in benefits allocation to any future inspection. As one of the middle managers puts it, " ... it is always good to have a potential backup to reason about your decisions." The issue that arises because of such reasoning is that it contradicts the purpose of the use of algorithms. Deciding with discretion about what is suitable for an unemployed person is a difficult challenge. The inclusion of technology should serve to help in reducing the challenge's burden and to contribute to the well-being of the unemployed. If technological affordances and human needs are improperly configured, conclusions about the effects of the algorithmic decision support systems may be misleading. Such implications are pertinent in the context of the debate of "rule vs. discretion" and valuing human judgment for serving individual justice (Binns 2019). The proponents of discretion-or human judgment-may find anecdotal or survey evidence of the weak performance of algorithmic decision-making in this research as an argument that bolsters their views. Or the proponents of full automation may view the strong preference for future use of algorithmic decision-making as clear support of their ideas. Maybe the debate should be directed toward designing different systems that resolve the paradox by rendering it obsolete. To this end, we propose potential governance systems in which citizens receive all the relevant information and make their choices, leaving counselors as professional support for citizens when the support is requested or, proactively, when a citizen is likely to experience an adverse effect in the near future.

In addition to the detachments previously considered, we argue that considerable attention needs to be paid to what is referred to as algorithmic brokerage (Kellogg, Valentine, and Christin 2020; Henke, Levine, and McInerney 2018), not only to interpret the outputs of algorithms but also to maintain the importance of generating accurate data and appropriate use as a strategic goal. The evidence presented in this study reinforces the views that human domain experts are no guarantee of adequate monitoring and frequently fail to manually override algorithmic decisions (Markus 2017). This highlights the need for algorithmic brokerage. At the same time, we argue for the necessity of what 
Kellogg, Valentine, and Christin (2020) refer to as algorithmic articulation, to not only understand the obstacles that prevent the appropriate use of the algorithmic decisionmaking but also to influence the development of the effective procedures that support the optimal involvement of the employees in decision-making without negative performative effects of their engagement.

The need for an effective organizational design becomes more pronounced if we consider a surprising finding of this study regarding the role given to the risk-assessment system by the organization. The provision of risk score, together with an organizational guide, through its use, became a recommender system even though such a configuration did not offer the capacity to become a recommender system. Some of the frustrations from the system-in-use originate precisely at the point of mislabeling of systems. We may speculate that the problem is in the constrained environment of a public agency, which does not have either the agility or the resources to develop the system to its potential although they are aware of it and are willing to develop it-as suggested by the middle management during the interviews. Additionally, the state in which the development of the system was frozen for almost a decade led to the emergence of new organizational behaviors and lower quality of data than what could have been collected (Cunha and Carugati 2018). The latter may be a form of penalizing future insights, which is, in most cases, avoidable. The importance of understanding these outcomes becomes obvious when we consider the profile of an organization-one that works to improve social welfare.

At the policymaking level, there seem to be strong incentives for public administration to move toward the heavy use of algorithms and large volumes of data to inform decisions (Gillingham 2019a; Wilcock 2016; Williamson 2014). The example provided by Raso (2017) demonstrates the eagerness of the governments to experiment and even circumvent some bureaucratic obstacles in order to implement algorithmic decision-making. What this and other studies show is that the elevated expectations from the algorithmic decision-making in practice are at best partially met. At the street level, the output of algorithms is often opaque, and instead of simplifying or enhancing decision-making, algorithms add to the complexity of the process. While in some of the studies, algorithms have been systematically overruled (e.g., Lebovitz, Levina, and Lifshitz-Assaf 2019) because of opacity, this study points to a larger issue that is relevant for the quality of the data collected. Frontline employees facing opaque decisions generated by algorithms may decide to: (i) ignore them but still register (often inaccurate) algorithmic output, as in this study; (ii) manipulate the output and save the manipulated (and often inaccurate) outcome (e.g., Raso 2017); (iii) overrule the algorithms, and register their decisions accordingly. Of the three, the last is the most appropriate option that should be considered as the design principle of the decision support systems in public administration.

Considering future research informed by this study, there are several interesting questions. A broad topic of artificialintelligence-era public management is still in the early stage of development, and many questions remain open. In line with our argument, algorithmic decision-making serves to support humans in the human-in-the-loop type of decision support systems. Given that opacity is a significant concern, as evidenced in this and other studies, it may be useful to understand the type and extent of information needed to empower human attachment and responsibility for decision-making. A challenge in this line of research is to disentangle the best possible algorithmic decision from the best practical decision for a client, a counselor, or the public agency. Also, given that the function of the counselors who work with the decision support systems has changed to include outputs of algorithms as part of the decision-making process, it may be useful to explore how different levels of employees' literacy about algorithms and different configurations of organizational factors influence the perceptions of the role of algorithms in decision-making, as well as the level of information needed to unlock the optimal assemblage of humans and algorithms. At the organizational level, the questions about what constitutes actionable intelligence as output from the data-driven decision support systems may be of interest when considering counselors and citizens/beneficiaries. On a public policy level, pertinent research questions are also related to the mitigation of fairness issues in the allocation of benefits in systems with different allocations of functions between humans and machines.

\section{CONCLUSIONS}

In this article, we present a study of a hybrid, human-computer decision-making system within the context of a public employment service. This research raises the pressing need to carefully rethink how the shift from new public management toward digital-era governance (Dunleavy et al. 2005) or, alternatively, artificial-intelligence-era governance is taking place. It reinforces the notion that algorithmic decision-making in use should be considered more broadly than just a function allocation problem between humans and computers, as elaborated by Dodou and de Winter (2014). Rather, algorithmic decision-making should be seen as a fundamental change in how we design processes, configure the interactions with technology, measure the impact, and especially in the public policy settings, a change in the agility to make changes and adjustments as technology evolves. The assemblage of human and machine agency needs to be achieved in a way that does not erode discretion (Beer 2017) or that serves as an administrative backing to decisions. In other words, it should neither promote algocracy (Danaher 2016) nor be mere bureaucratic decoration. The assemblage should reinforce the purpose of the public administration and improve its legitimacy with respect to the properties and outcomes of its procedures (Danaher 2016)-to deliver the appropriate assistance to each citizen who requests it, in a human way, fair, and at scale.

As we conducted this study, we became more aware that although fairness and biases of algorithms are common in public discourse and academic literature (e.g., Zerilli et al. 2019; Lepri et al. 2018), in practice we lack systematic action that deals with such issues in decision-making regardless of the level of reliance on algorithms or humans. Such action may be easier in fully automated systems, but deliberate efforts to analyze and discuss the registered benefits with respect to potential systematic disparities between social groups that have different underlying (dis)advantages seem like a good step forward.

\section{ACKNOWLEDGMENTS}

We acknowledge financial support from Fundação para a Ciência e Tecnologia (UID/ECO/00124/ 2013) by LISBOA-01-0145-FEDER007722, Social Sciences Data Lab, Project 22209, and the Project of Scientific Research and Technological Development in Data Science and Artificial Intelligence in Public Administration. 
We are grateful to Cristina Faro, Cristina Taveira, Carlos Santana, Maria José Pedro and the IEFP staff for their support regarding this research. We are also grateful to Lénia Mestrinho from the Data Science Knowledge Center for her project management, and to two reviewers and the special issue editors for their invaluable comments that significantly improved the paper.

\section{CONTRIBUTIONS}

Leid Zejnilović initiated and contributed to designing the study and its execution, participated in the analysis, and in the writing of the article.

Susana Lavado participated in the design of the study, in its execution, in the analysis of the qualitative part, and in the writing of the article.

Ínigo Martínez de Rituerto de Troya participated in the design of the qualitative parts of the study, in the execution and analysis of the qualitative part, and in the writing of the article.

Andrew Bell participated in some of the elements of the design of the qualitative part of the study, and in the writing of the article.

Samantha Sim participated in the survey design and contributed to the writing of the article.

\section{AUTHOR BIOGRAPHIES}

Leid Zejnilović is an Assistant Professor at Nova School of Business and Economics. He received his Ph.D. in Technological Change and Entrepreneurship from Carnegie Mellon University and the Catholic University of Portugal. His research interest is in Technology and Innovation Manage- ment. Leid is the founder and academic co-director of the Data Science Knowledge Center at Nova School of Business and Economics, and a co-founder and Chairman of Data Science for Social Good Foundation.

Susana Lavado is a postdoctoral researcher in the Data Science Knowledge Center at Nova School of Business and Economics, where she works in partnership with the Portuguese Employment and Training Institute (Instituto de Emprego e Formação Profissional - IEFP). She has a Ph.D. in Social Psychology from the University of Lisbon and a Master Degree in Advanced Analytics from Nova Information Management School.

Íñigo Martínez de Rituerto de Troya is a research fellow in the Data Science Knowledge Center at Nova School of Business and Economics. He is an alumni of the Data Science for Social Good Fellowship, and has an MEng in Electrical \& Electronic Engineering from Imperial College London and an MRes in Neuroinformatics \& Computational Neuroscience from The University of Edinburgh.

Samantha Sim is an Assistant Professor at Nova SBE. She received her Ph.D. in Business from Singapore Management University. Her research interests are in Organizational Behavior, specifically compassion and mindfulness at the workplace. She is also a member of the Leadership for Impact Centre at Nova SBE and Mindfulness Initiative at Singapore Management University.

Andrew Bell is an assistant adjunct lecturer at the Nova School of Business of Economics, and a data scientist in the Data Science Knowledge Center. He is an alumni of the Data Science for Social Good Fellowship, and received a B.S. in Mathematical Sciences from Clemson University. 


\section{REFERENCES}

Ackermann, Klaus, Joe Walsh, Adolfo De Unánue, Hareem Naveed, Andrea Navarrete Rivera, Sun-Joo Lee, Jason Bennett, et al. 2018. "Deploying Machine Learning Models for Public Policy: A Framework.” In Proceedings of the 24th ACM SIGKDD International Conference on Knowledge Discovery \& Data Mining. ACM. https://doi.org/10.1145/3219819.3219911.

Ajzen, Icek. 1991. “The Theory of Planned Behavior.” Organizational Behavior and Human Decision Processes 50 (2): 179-211. https://doi.org/10.1016/07 49-5978(91)90020-t.

Ananny, Mike, and Kate Crawford. 2018. “Seeing without Knowing: Limitations of the Transparency Ideal and Its Application to Algorithmic Accountability.” New Media \& Society 20 (3): 973-89. https://doi.org/10.1177/1461444816676645.

Bader, Verena, and Stephan Kaiser. 2019. "Algorithmic Decision-Making? The User Interface and Its Role for Human Involvement in Decisions Supported by Artificial Intelligence.” Organization 26 (5): 655-72. https://doi.org/10.1177/13505084198557 14.

Becker, Sascha O., Ana Fernandes, and Doris Weichselbaumer. 2019. "Discrimination in Hiring Based on Potential and Realized Fertility: Evidence from a Large-Scale Field Experiment.” Labour Economics 59 (August): 139-52. https://doi.org/10.10 16/j.labeco.2019.04.009.

Beer, David. 2017. “The Social Power of Algorithms.” Information, Communication \& Society 20 (1): 1-13. https://doi.org/10.1080/1369118x.2016.1216147.

Bethlehem, Jelke. 2010. "Selection Bias in Web Surveys.” International Statistical Review 78 (2): 161-88. https://doi.org/10.1111/j.1751-5823.2010.00 112.x.

Binns, Reuben. 2019. “Human Judgement in Algorithmic Loops; Individual Justice and Automated Decision-Making." Available at SSRN. https://doi.org/ 10.2139/ssrn.3452030.

Braun, Virginia, Victoria Clarke, Nikki Hayfield, and Gareth Terry. 2019. “Thematic Analysis.” In Handbook of Research Methods in Health Social Sciences, edited by P. Liamputtong , 843-60. Singapore: Springer Singapore. https://doi.org/10.100 7/978-981-10-5251-4_103.
Burrell, Jenna. 2016. “How the Machine 'Thinks': Understanding Opacity in Machine Learning Algorithms.” Big Data \& Society 3 (1): 1-12. https://d oi.org/10.1177/2053951715622512.

Carlsson, Magnus, and Stefan Eriksson. 2019. “Age Discrimination in Hiring Decisions: Evidence from a Field Experiment in the Labor Market." Labour Economics 59 (August): 173-83. https://doi.org/10.10 16/j.labeco.2019.03.002.

Caswell, Dorte, Greg Marston, and Jørgen Elm Larsen. 2010. “Unemployed Citizen or 'at Risk' Client? Classification Systems and Employment Services in Denmark and Australia." Critical Social Policy 30 (3): 384-404. https://doi.org/10.1177/0261018310367674.

Catlett, Charlie, and Rayid Ghani. 2015. "Big Data for Social Good.” Big Data 3 (1): 1-2. https://doi.org/10.1 089/big.2015.1530.

Cunha, Joao, and Andrea Carugati. 2018.

"Transfiguration Work and the System of Transfiguration: How Employees Represent and Misrepresent Their Work.” Mis Quarterly 42 (3): 873-94. https://doi.org/10.25300/misq/2018/13050.

Danaher, John. 2016. "The Threat of Algocracy: Reality, Resistance and Accommodation.” Philosophy \& Technology 29 (3): 245-68. https://doi.org/10.100 7/s13347-015-0211-1.

Diette, Timothy M., Arthur H. Goldsmith, Darrick Hamilton, and William Darity Jr. 2012. "Causality in the Relationship between Mental Health and Unemployment.” In Reconnecting to Work: Policies to Mitigate Long-Term Unemployment and Its Consequences, 63-94. W.E. Upjohn Institute. http s://doi.org/10.17848/9780880994095.ch4.

Dodou, D., and J.C.F. de Winter. 2014. "Social Desirability Is the Same in Offline, Online, and Paper Surveys: A Meta-Analysis." Computers in Human Behavior 36 (July): 487-95. https://doi.org/10.1016/j.c hb.2014.04.005.

Dunleavy, Patrick, Helen Margetts, Simon Bastow, and Jane Tinkler. 2005. "New Public Management Is Dead-Long Live Digital-Era Governance.” Journal of Public Administration Research and Theory 16 (3): 467-94. https://doi.org/10.1093/jopart/mui057.

Foddy, William. 1993. Constructing Questions for Interviews and Questionnaires: Theory and Practice in Social Research. Cambridge: Cambridge University Press. https://doi.org/10.1017/cbo9780511518201. 
Gillespie, Tarleton, Pablo J. Boczkowski, and Kirsten A. Foot, eds. 2014. Media Technologies: Essays on Communication, Materiality, and Society. Cambridge, MA: The MIT Press. https://doi.org/10.7551/mitpress/ 9780262525374.001.0001.

Gillingham, Philip. 2019a. “Can Predictive Algorithms Assist Decision - Making in Social Work with Children and Families?" Child Abuse Review 28 (2): 114-26. https://doi.org/10.1002/car.2547.

- - . 2019b. "The Development of Algorithmically Based Decision-Making Systems in Children's Protective Services: Is Administrative Data Good Enough?" The British Journal of Social Work 50 (2): 565-80. https://doi.org/10.1093/bjsw/bcz157.

Günther, Wendy Arianne, Mohammad H. Rezazade Mehrizi, Marleen Huysman, and Frans Feldberg. 2017. "Debating Big Data: A Literature Review on Realizing Value from Big Data." The Journal of Strategic Information Systems 26 (3): 191-209. https://doi.org/ 10.1016/j.jsis.2017.07.003.

Harris, Jeanne G., and Thomas H. Davenport. 2005. "Automated Decision Making Comes of Age." MIT Sloan Management Review 46 (4): 2-10.

Henke, N., J. Levine, and P. McInerney. 2018. "You Don't Have to Be a Data Scientist to Fill This MustHave Analytics Role." Harvard Business Review, February. https://hbr.org/2018/02/you-dont-have-tobe-a-data-scientist-to-fill-this-must-have-analytics-r ole.

Hennion, Antoine. 2017. “Attachments, You Say? ... How a Concept Collectively Emerges in One Research Group." Journal of Cultural Economy 10 (1): 112-21. https://doi.org/10.1080/17530350.2016.1260 629.

Hood, Christopher, and Guy Peters. 2004. “The Middle Aging of New Public Management: Into the Age of Paradox?" Journal of Public Administration Research and Theory 14 (3): 267-82. https://doi.org/1 0.1093/jopart/muh019.

Hupe, Peter. 2019. "Contextualizing Government-inAction.” In Research Handbook on Street-Level Bureaucracy, edited by Peter Hupe. Cheltenham, UK: Edward Elgar Publishing. https://doi.org/10.4337/978 1786437631.

Isenberg, D.J. 1986. “Group Polarization: A Critical Review and Meta-Analysis".” Journal of Personality and Social Psychology 50 (6): 1141-51. https://doi.or g/10.1037/0022-3514.50.6.114.
Kagan, Robert. 2010. “The Organisation of Administrative Justice Systems: The Role of Political Mistrust.” In Administrative Justice in Context, edited by Michael Adler, 161-82. Oxford: Hart Publishing.

Kellogg, Katherine C., Melissa A. Valentine, and Angéle Christin. 2020. "Algorithms at Work: The New Contested Terrain of Control.” Academy of Management Annals 14 (1): 366-410. https://doi.org/ 10.5465/annals.2018.0174.

Kübler, Dorothea, Julia Schmid, and Robert Stüber. 2018. "Gender Discrimination in Hiring across Occupations: A Nationally-Representative Vignette Study." Labour Economics 55 (December): 215-29. htt ps://doi.org/10.1016/j.labeco.2018.10.002.

Lavalle, Steve, Eric Lesser, Rebecca Shockley, Michael S. Hopkins, and Nina Kruschwitz. 2011. "Big Data, Analytics and the Path from Insights to Value." MIT Sloan Management Review 52 (2): 21-32.

Lebovitz, Sarah, Natalia Levina, and Hila LifshitzAssaf. 2019. "Doubting the Diagnosis: How Artificial Intelligence Increases Ambiguity during Professional Decision Making.”

Lepri, Bruno, Nuria Oliver, Emmanuel Letouzé, Alex Pentland, and Patrick Vinck. 2018. "Fair, Transparent, and Accountable Algorithmic Decision-Making Processes.” Philosophy \& Technology 31 (4): 611-27. https://doi.org/10.1007/s13347-017-0279-x.

Lepri, Bruno, Jacopo Staiano, David Sangokoya, Emmanuel Letouzé, and Nuria Oliver. 2017. “The Tyranny of Data? The Bright and Dark Sides of DataDriven Decision-Making for Social Good." In Studies in Big Data, edited by T. Cerquitelli, D. Quercia, and F. Pasquale, 32:3-24. Cham: Springer International Publishing. https://doi.org/10.1007/978-3-319-5402 4-5 1 .

Lipsky, Michael. 2010. Street-Level Bureaucracy: Dilemmas of the Individual in Public Service. 30th Ann. Ed. New York: Russell Sage Foundation.

Loxha, Artan, and Matteo Morgandi. 2014. "Profiling the Unemployed: A Review of OECD Experiences and Implications for Emerging Economies.” Social Protection \& Labour Discussion Paper, No. 1424, World Bank. https://openknowledge.worldbank.org/h andle/10986/20382.

Markus, M. Lynne. 2017. “Datification, Organizational Strategy, and IS Research: What's the Score?” The Journal of Strategic Information Systems 26 (3): 233-41. https://doi.org/10.1016/i.jsis.2017.08.003. 
Matty, Simon. 2013. “Predicting Likelihood of LongTerm Unemployment: The Development of a UK Jobseekers' Classification Instrument.” Working Paper 116, Department for Work and Pensions. 2013. http s://assets.publishing.service.gov.uk/government/uplo ads/system/uploads/attachment_data/file/210303/WP 116.pdf.

Möhlmann, Mareike, and Lior Zalmanson. 2017. "Hands on the Wheel: Navigating Algorithmic Management and Uber Drivers' Autonomy.” In Proceedings of the International Conference on Information Systems (ICIS), 10-13, 10-13. Seoul, South Korea.

Morgan, David. 1997. Focus Groups as Qualitative Research. SAGE Publications, Inc. https://doi.org/10.4 135/9781412984287.

Mostafavi, Behrooz, Zhongxiu Liu, and Tiffany Barnes. 2015. "Data-Driven Proficiency Profiling.” In International Conference on Educational Data Mining (EDM 2015), 249-52.

Newell, Sue, and Marco Marabelli. 2015. "Strategic Opportunities (and Challenges) of Algorithmic Decision-Making: A Call for Action on the Long-Term Societal Effects of 'Datification." The Journal of Strategic Information Systems 24 (1): 3-14. https://d oi.org/10.1016/j.jsis.2015.02.001.

O’Connell, Philip, Seamus McGuinness, and Elish Kelly. 2010. "A Statistical Profiling Model of LongTerm Unemployment Risk in Ireland.” ESRI Working Paper 345.

Payne, Clive, and Joan Payne. 2000. "Early Identification of the Long-Term Unemployed. PSI Research Discussion Paper 4.” London: Policy Studies Institute. http://www.psi.org.uk/site/publication_deta il 1269.

Pearson, Danielle, and Andreas Vossler. 2016. "Methodological Issues in Focus Group Research: The Example of Investigating Counsellors' Experiences of Working with Same-Sex Couples." Counselling Psychology Review 31 (1): 1-22. http://oro.open.ac.u k/id/eprint/45615.

Raso, Jennifer. 2017. “Displacement as Regulation: New Regulatory Technologies and Front-Line Decision-Making in Ontario Works." Canadian Journal of Law and Society / Revue Canadienne Droit et Société 32 (01): 75-95. https://doi.org/10.1017/cl s.2017.6.

Riipinen, T. 2011. “Risk Profiling of Long-Term Unemployment in Finland." In PowerPoint Presentation at the European Commission's "PES to PES Dialogue Dissemination Conference.” Brussels, September 8-9, 2011.
Scoppetta, Anette, and Arthur Buckenleib. 2018. "Tackling Long-Term Unemployment through Risk Profiling and Outreach.” European Union Technical Dossier, no. 6. https://doi.org/10.2767/677020.

Simonite, Tom. 2015. “Teaching Machines to Understand Us.” MIT Technology Review 118 (5): 70-77.

Strauch, Barry. 2018. "Ironies of Automation: Still Unresolved after All These Years.” IEEE Transactions on Human-Machine Systems 48 (5): 419-33. https://d oi.org/10.1109/thms.2017.2732506.

Sunstein, Cass R. 2012. "Regulation in an Uncertain World." In Speech before the National Academy of Sciences Government-University-Industry Roundtable Meeting. Vol. 20. Washington, DC.

Sztandar-Sztanderska, Karolina, and Marianna Zielenska. 2018. "Changing Social Citizenship through Information Technology.” Social Work \& Society 16 (2): 1-13.

Venkatesh, Viswanath, James Thong, and Xin Xu. 2016. "Unified Theory of Acceptance and Use of Technology: A Synthesis and the Road Ahead." Journal of the Association for Information Systems 17 (5): 328-76. https://doi.org/10.17705/1jais.00428.

Wagner, Ben. 2019. "Liable, but Not in Control? Ensuring Meaningful Human Agency in Automated Decision-Making Systems.” Policy \& Internet 11 (1): 104-22. https://doi.org/10.1002/poi3.198.

Weber, Tina. 2011. "Profiling Systems for Effective Labour Market Integration.” In The European Commission Mutual Learning Programme for Public Employment Services.

Wilcock, Scarlet. 2016. "Policing Welfare: Risk, Gender and Criminality.” International Journal for Crime, Justice and Social Democracy 5 (1): 113. http s://doi.org/10.5204/ijcisd.v5i1.296.

Williamson, Ben. 2014. "Knowing Public Services: Cross-Sector Intermediaries and Algorithmic Governance in Public Sector Reform." Public Policy and Administration 29 (4): 292-312. https://doi.org/1 $0.1177 / 0952076714529139$.

Zacka, Bernardo. 2017. When the State Meets the Street. Cambridge, MA: Harvard University Press. htt ps://doi.org/10.4159/9780674981423.

Zerilli, John, Alistair Knott, James Maclaurin, and Colin Gavaghan. 2018. “Transparency in Algorithmic and Human Decision-Making: Is There a Double Standard?” Philosophy \& Technology 32 (4): 661-83. https://doi.org/10.1007/s13347-018-0330-6. 
2019. "Algorithmic Decision-Making and the Control Problem.” Minds and Machines 29 (4):

555-78. https://doi.org/10.1007/s11023-019-09513-7. 